report on the first eighteen months' work of the ethnographical department of the Geological Survey of Canada, which, it will be remembered, was a direct outcome of the visit of this Association to Winnipeg in Igo9, and Dr. Hrdlička, in a letter from Siberia addressed to the President, announced that he had discovered in north-eastern Asia living representatives of the ancient race which gave North America its Indians.

\section{BIRD NOTES.}

I $\mathrm{N}$ an article on the food of nestling birds published in the Journal of the Board of Agriculture for September, I9i2, Mr. W. E. Collinge commences by referring to the fact that in the early stages of life birds daily consume more than their own weight of food. It is also mentioned that since nearly all birds except pigeons feed their young upon an animal diet, and that the nesting season occurs when insects are most abundant, the value of birds as insect-destroyers is self-apparent.

In Witherby's British Birds for October an instance of one cuckoo laying in the nest of a marsh-warbler and of a second in that of a rock-pipit are recorded. Only about five instances of a similar event have been previously recorded in the case of each species.

To The Zoologist for October Mr. Harvie Brown contributes the first part of an article on the past and present distribution of the fulmar petrel on both sides of the Atlantic, and its recent spread in northern Britain.

For about a century naturalists were content with the name Strix flammea for the barn-owl. The late Prof. Newton proposed to replace the generic name by Aluco, but this usage was recently stated by $\mathrm{Mr}$. G. M. Mathews to be invalid. In No. 4 of The Austral Avian Record, after referring to a couple of alternative generic designations, the same writer brings forward the name Flammea vulgaris as one to which no objection can be taken. It seems a pity to try to displace a name which has become almost a household word. This replacement of long-accepted names of British birds by others of earlier date forms the subject of an editorial article in the September number of The Scottish Naturalist, where it is remarked that "though our sympathies are strongly in favour of the British Association's rules, yet we are willing to view the present situation in a liberal spirit. There must, however, be concessions, and we regard it as essential that a number of time-honoured names must be conserved."

In the above-mentioned issue of The Scottish Naturalist, Mr. Eagle Clarke describes, with an illustration, a male hybrid between an eider drake and a wild duck, which was shot early in 1912 in the Orkneys. What appears to have been a fellow-hybrid was seen on the Pentland Skerries in the following May. No other instance of a similar hybrid appears to be on record.

We are indebted to Mr. W. Junk, of Berlin, for a copv of a sale catalogue of ornithological literature. R. I.

\section{REPORT OF THE METEOROLOGICAL COMMITTEE.}

THE report of the Meteorological Committee tor the year ended March 3I, I912, shows that several important matters were dealt with during that period, e.g. the reconsideration of the relations with the Post Office as regards weather telegraphy, the incorporation in the official network of stations which NO. 2247, voL. 90] had previously sent their observations to the Royal Meteorological Society, the publication of results of various classes of observations, and the revision of rules under which the increasing number of telegraphic reports from health resorts can be accepted for communication to the Press.

The present capabilities of international and wireless weather telegraphy are well jllustrated by the frontispiece synoptic chart for April 1 of the distribution of weather phenomena over a large part of the northern hemisphere compiled from data received within ten days of the date of the chart. One great advantage has been conceded by the Post Office at the request of H.M. Treasury in allowing priority of transmission to certain classes of meteorological telegrams and to storm warnings; but very much still remains to be effected in the way of facilitating the telegraphic distribution of forecasts to all parts of the United Kingdom by some financial arrangement by which the Meteorological Office would be placed on a better footing in carrying out its important public work than that accorded to a "private person."

The percentage of complete success and the sum of successes (complete and partial) of the $8 \mathrm{~h}$. $30 \mathrm{~m}$. p.m. forecasts for the year IgII were both higher than in any year since 1879, when the present service of daily forecasts was inaugurated. The "further outlook" frequently appended to the forecasts for twentyfour hours has also been remarkably successful. Want of space precludes special mention here of the useful work carried on in other departments of the office.

\section{THE METALS IN ANTIQUIT'Y.}

$T$ HE Huxley memorial lecture was given by Prof. W. Gowland, F.R.S., on Tuesday, November 19, at the Royal Anthropological Institute, the subject being "The Metals in Antiquity." After pointing out the sources whence our knowledge of the use of metals by man in prehistoric and protohistoric times was derived, the lecturer gave an account of the primitive metallurgy of copper, tin, gold, lead, silver, and iron, the conditions under which they were extracted from their ores, and the localities in which they were first obtained.

The origin of the smelting furnace was traced to the camp fire, in which, if by chance a lump of ore either of copper carbonate, tin-stone, or brown iron ore or hrematite, had been one of the ring of stones surrounding the camp or domestic fire and had accidentally become embedded in its embers, it would undoubtedly be reduced to metal.

The metals which occur-native copper, gold, and iron-were undoubtedly the first to be known to man in the localities in which they occurred, but until the art of smelting metals had been invented, the discovery and use of the native metals was insufficient to affect to any great extent the old Stone age culture.

Gold, although doubtless the first metal to be known in many localities owing to its wide distribution in the sands of rivers, was useless for any practical purpose.

Copper, however, or an alloy of the metal with tin, antimony, or arsenic, was extracted from ores at a verv remote period, and it or its alloys was the first to be applied to practical use. In fact, the first metal to be obtained by primitive man by smelting copper ores depended on their composition, and in the localities where tin did not occur it was a more or less impure copper.

The extraction of gold from its ores on a large scale in the earliest times was attributed to the Sudan 
district of Egypt, and the primitive tools and methods employed at the mines were described.

Egypt was also noted for having produced the first mining map in the world, a map showing a gold mining region of the time of Seti I. or Rameses II. (i350 to 1330 B.C.).

The influence of silver and lead on the development of primitive culture was shown to be insignificant, the latter metal only becoming of importance during the supremacy of the Romans, in connection with their elaborate systems for the supply and distribution of water and in the construction of baths.

As regards iron, the belief that the first iron generally known to man was either of meteoric origin or telluric native iron was not supported by any substantial evidence. Nor was such origin necessary, as iron ores are so easily reducible that they can be converted into metallic iron in an ordinary charcoal fire. They are, in fact, reduced to metal at a considerably lower temperature than the ores of copper.

The earliest iron smelting in Europe was traced to the upper waters of the Danubian tributaries, the ancient Noricum, but in still earlier times iron was extracted from its ores in the region on the south-east of the Euxine, in Ferghana and other localities in Asia. In Africa, so far as metallurgical evidence may be depended on, the extraction of iron from its ores was carried on at a remote date. That this early African iron smelting was known in Egypt is well shown by a bas-relief on a stone now in the Egyptian collection in Florence.

\section{THE BORDERLAND BETWEEN ELEC- TRICITY AND OTHER SCIENCES. ${ }^{1}$}

THERE are applications of electricity that give work to many men, applications which employ much plant and apparatus, and on which large sums of money are spent, about which we have heard very little or nothing in the institution. Again, we hear little, if anything, about what is occurring on what I may term the borderland between electricity and the other sciences. In this borderland or fringe a large number of scientific workers are quietly at work, and what is to-day a laboratory experiment may to-morrow form the basis of a large industry. Finally, we should have an opportunity of discussing the many details in the design and operation of electrical plant and apparatus, the importance of which cannot be overestimated.

IVireless Telegraphy and Telephony.-Corresponding to each spark at the transmitter of a wireless telegraphy plant, a train of oscillations is received, and these trains of oscillations are rectified by the detector, and in general are passed through a telephone as an indicator. At each spark a click is heard in the telephone, so that with 600 sparks a second the diaphragm is attracted 600 times, producing a somewhat musical note.

Herein lies one of the great advantages of highspark frequency.

There seems no doubt that the combination of the human ear and a telephone is much more sensitive for high-frequency notes than for low. In some tests I have made, using an alternating current to determine the minimum power required to produce an audible signal in a telephone receiver at different frequencies, I found in one case that the power was reduced from 430 micro-microwatts at 300 frequency to 7.7 micro-microwatts at 900 frequency. At higher frequencies it increased again. I From the presidential address delivered to the Institution of Electrical
Engineers on November 44 by Mr. W. Duddell, F.R.S.

NO, 2247, VOL. 9O]
Due to atmospheric causes, there is generally audible in the telephone receiver clicks and noises commonly spoken of as atmospherics or strays. With highspark frequencies the human ear easily distinguishes the musical note from these atmospherics; this enables the operators to read through a large amount of extraneous interference. The elimination or compensation of these atmospherics is one of the most important outstanding problems in wireless telegraphy.

When operating with continuous waves practically no note is heard in the receiver telephone unless the currents are chopped up into rapidly recurring groups of waves either at the transmitter (tone sender) or at the receiving end (ticker).

In order to make a permanent record of the signals, and to allow of high-speed working, the rectified current from the detector may be passed through a galvanometer or a relay, and here we come to one of the difficult problems which requires solution, namely the construction of a relay or recording instrument which will make a record of the very small received currents at high speeds. The Einthoven or string galvanometer, which is at present used for this purpose, is delicate and gives a photographic record.

Although the difficulties may be minimised, I do not feel at this moment that the photographic method of recording, with the attendant chemicals, and the necessity of handling moist slip, can be looked upon as the final solution from the point of view of commercial telegraphy.

The problem of constructing a relay for this purpose is a very difficult one. The mean current strength of the signals, after rectification by a high-resistance detector, is of the order of $\frac{\pi}{10}$ to $\frac{1}{10 \pi}$ of a microampere, and the amount of power available to work the instrument is only of the order of a few micro-microwatts. For high-speed reception the number of contacts to be made and broken per second may be anything up to fifty. The problem before our instrumentmakers is to construct a relay or recorder which will operate with a power not exceeding a few micromicrowatts at the rate of fifty signals per second.

Of the sister science, namely wireless telephony, there is not so much to relate. A certain amount of progress has been made, but the details of the methods used have not been made public. The principle is simple. Given continuous oscillations or a spark frequency above the limits of audibility, you may vary the antenna current, and hence the radiation by means of a microphone, in the same way as a continuous current is varied by the microphone in ordinary telephony. As the radiation varies according to the modulation of the current by the voice the received current will be varied in the same manner and the voice will be reproduced. The difficulties are mainly in the transmitter. First, we require a perfectly steady source of continuous oscillations, and secondlv a microphone capable of modulating the large powers required to transmit any distance. Over short distances of a few miles there are no difficulties. It is only when we come to distances of fifty to roo miles that the engineering problems become troublesome. In view of the progress that is being made in the high-frequency alternator, and of how much more easy it is to modify the power given out by an alternator, it will not be surprising if, as soon as high-frequency alternators are in use, wireless telephony over comparatively long distance becomes a working possibility. Electrochemistry and Electrometallurgy. - The amount of power installed for chemical and metallurgical purposes is very large indeed. Exact data are wanting, but it seems probable that the power employed in these processes in Norwav and at Niagara may already reach $\mathrm{I}, 000,000 \mathrm{kw}$. One of the neces- 